\title{
PEREMPUAN DAN INTERNET DALAM PENINGKATAN EKONOMI KELUARGA
}

\author{
WOMEN AND THE INTERNET \\ IN IMPROVING FAMILY ECONOMICS
}

\author{
Oleh: \\ Susri Adeni, Sudani Herman, dan Dedi Supriyadi \\ Fakultas Ilmu Sosial dan Ilmu Politik Universitas Bengkulu
}

\begin{abstract}
In addressing the problem of poverty, the media also has a very important role. In addition, with media, especially the internet, we can find out information about the weather and the sea and fishing information globally accessible. Further explained that the resources of this example is FIGIS (fisheries global information system) that provides a range of statistical information such as fisheries, fish distribution maps by species, issue and topic of the actual fisheries, aquaculture, marine fisheries, and fishing technology. The data is available anytime and anywhere needed. Based on the background is exactly the service activities based on this urgent research to be conducted. The activity goal is to provide knowledge for women and families of fishermen on the media, especially the Internet and equip the women and families of fishermen to learn new media like the internet. The target audience of the utilization of the internet is for girls and coastal fishing families who live in the city of Bengkulu Malabero coastal areas totaling 10 people who have a product that can be sold in the market. The activities are lectures, discussions and simulations use the internet with the ultimate goal the establishment of a blog that can be used to sell their products.
\end{abstract}

Keywords: Internet, women, economics, blogs, information

\section{PENDAHULUAN}

Kemiskinan menjadi masalah berkepanjangan di Indonesia. Hal ini terbukti dengan begitu banyak program pemerintah yang dikeluarkan dalam mengatasi masalah kemiskinan. Hal ini dilakukan untuk dapat meningkatkan taraf hidup dan kesejahteraan masyarakat. Demikian juga yang terjadi di Kota Bengkulu. Berbagai program penangulangan kemiskinan diluncurkan agar dapat membantu penduduk dengan kategori miskin baik yang berada di daerah pesisir maupuan di tempat lainnya. Dilihat lebih jauh mengenai kesejahteraan rakyat secara spesifik, di Kota Bengkulu masih terdapat banyak warga yang dikategorikan miskin. Dari data BPS Provinsi Bengkulu, jumlah penduduk miskin yang ada di Kota Bengkulu pada tahun 2006 adalah 24.200 atau 9.28\% (BPS, 2007:25) meningkat menjadi 25.700 jumlah penduduk miskin atau 9.20\% ditahun 2007 (BPS, 2008:28) dan 52.200 jumlah penduduk miskin atau 18.16\% di tahun 2008 (BPS, 
2008:44). Dari data tersebut, terlihat terjadi peningkatan jumlah penduduk miskin di Kota Bengkulu. Bahkan data terakhir menunjukkan jumlah Rumah Tangga Miskin (RTM) di Kota Bengkulu mencapai 20.312 RTM (Pemkot Bagian Perekonomian, Kota Bengkulu, 2009). Data juga menunjukkan, pada umumnya kantong-kantong kemiskinan yang sangat tinggi adalah di daerah pesisir. Angka kemiskinan yang ada di daerah pesisir di Kota Bengkulu sebanyak 4.641 RTM, atau sekitar 24\% (Adeni, Kartika, dan Andani, 2010:1).

Dalam mengatasi masalah kemiskinan, media juga mempunyai peranan yang sangat penting. Telah banyak penelitian sebelumnya yang melihat bagaimana media atau Information Communication Technologies (ICTs, yang selanjutkan akan disingkat dalam artikel ini) atau yang lebih berfokus pada internet, seharusnya dapat membantu masyarakat dalam small-scale business dan informasi kelautan lainnya. Kementerian Kelautan dan Perikanan pun telah mengeluarkan program penggunaan internet untuk informasi kelautan. Hal ini karena nelayan mengalami keterbatasan alat tangkap terutama kapal dan SDM yang memiliki kompetensi teknologi tentang kelautan dan perikanan. Selain itu, dengan adanya internet dapat mengetahui informasi tentang laut dan cuaca serta informasi perikanan global dapat diakses. Lebih lanjut diterangkan bahwa sumber informasi ini contohnya adalah FIGIS (fisheris global information system) yang menyediakan berbagai informasi seperti statistik perikanan, peta sebaran ikan menurut spesies, issue dan topik perikanan aktual, budidaya, perikanan laut dan teknologi penangkapan. Data tersebut tersedia kapan dan dimana saja perlukan. Selain itu badan PBB FAO juga telah menyediakan data dan informasi penting tentang bagaimana profil perikanan di suatu negara dapat dipilih dengan mudah melalui situsnya. Adanya pemanfaatan media internet, dapat membantu perempuan dan keluarga nelayan dalam meningkatkan perekonomian keluarga.

Pada dasarnya, di Indonesia dan di Bengkulu sendiri, sangat banyak masyarakat yang menggunakan berbagai macam media dari handphone sampai internet sebagai salah satu pemenuhan kebutuhan akan hiburan dan informasi. Namun, di Indonesia khususnya Bengkulu, belum terlihat adanya pemanfaatan media internet bagi perempuan dan keluarga nelayan di pesisir Kota Bengkulu untuk mendapatkan informasi yang bermanfaat mengenai kelautan. Sementara bila dibandingkan dengan negara lainnya, internet menjadi salah satu sarana bagi nelayan untuk dapat meningkatkan produktivitas mereka dalam berusaha. Pemanfaatan internet dapat berupa memasarkan hasil produksi atau sebagai informasi jumlah ikan dan sebaran ikan yang ada. Selain itu, pada umumnya perempuan di daerah pesisir juga memiliki usaha untuk membantu perekonomian keluarga seperti pembuatan keripik dari ikan beledang atau jenis makanan lainnya. Namun pada kenyataannya, pemasaran yang dilakukan masih di tingkat lokal dan belum mampu memanfaatkan media yang untuk meningkatkan keuntungan. Sementara itu telah ada ada penelitian yang meneliti lebih dalam tentang pemanfaatan ICTs untuk meningkatkan dan membantu ekonomi keluarga di daerah pesisir di beberapa negara berkembang seperti di Malaysia, India, Afrika dan lainnya. Di Indonesia sendiri, belum banyak penelitian serupa, namun penulis telah melakukan penelitian di tahun 2012 tentang pemanfaatan media 
terutama internet bagi perempuan untuk peningkatan ekonomi keluarga. Sehingga dari penelitian tersebut, proposal pengabdian ini menjadi penting dan urgent untuk membantu perempuan dan keluarga nelayan dalam pendidikan media internet dalam upaya menyebarkan informasi dan membantu meningkatkan produksi serta perekonomian keluarga.

Lebih spesifik, kegiatan pemanfaatan media internet untuk perempuan dan nelayan ini akan dipusatkan di Kelurahan Malabro Kecamatan Teluk Segara. Hal ini dikarenakan penelitian terdahulu yang dilakukan oleh peneliti melibatkan perempuan di daerah tersebut. Sehingga dirasakan perlu bagi mereka untuk mendapatkan pengetahuan dan pendidikan lebih lanjut mengenai media internet dan pemanfaatannya. Diharapkan dengan adanya kegiatan ini, mereka dapat memanfaatkan media yang ada untuk meningkatkan produktiviats mereka sebagai nelayan. Berdasarkan hasil survey tim pada bulan Maret 2013, maka dapat dirumuskan masalah yang perlu ditangani, yaitu:

1. Kurangnya pengetahuan perempuan dan keluarga nelayan mengenai media khususnya internet.

2. Terbatasnya sumberdaya yang mengetahui tentang media khususnya internet.

3. Adanya keinginan yang kuat untuk mempelajari new media tapi keterbatasan akan informasi mengenai internet.

\section{METODE PENGABDIAN}

Berdasarkan permasalahan tersebut, maka diperlukan pendidikan dan pelatihan terhadap kelompok perempuan dan masyarakat nelayan tersebut. Pendidikan dan pelatihan yang dilakukan adalah dengan metode berikut:

1. Ceramah dan diskusi

Ceramah disini maksudnya adalah pembelajaran atau tanya jawab untuk melihat dan menggali seberapa dalam pengetahuan para perempuan dan keluarga nelayan mengenai media internet. Kegitan ceramah ini merupakan sebuah 'transfer of knowledge' dengan tujuan untuk meningkatkan pengetahuan mereka. Materi penyuluhan atau ceramah adalah perkembangan teknologi komunikasi dan media internet.

2. Pelatihan

Setelah dilakukan ceramah atau penyuluhan bagi para prempuan dan keluarga nelayan yang terlibat, selanjutnya dilakukan pengenalan media dan pelatihan internet bagi para peserta. Adapun pelatihan yang dilakukan meliputi: pengenalan komputer dan sistem aplikasi, penggunaan dan pemanfaatan internet, pengenalan situs-situs internet, serta terakhir adalah pembuatan blog. 


\section{HASIL DAN PEMBAHASAN}

Perkembangan teknologi komunikasi di Indonesia juga mengalami pertumbuhan yang sangat pesat. Media komunikasi di Indonesia dimanfaatkan oleh berbagai kalangan baik dari remaja hingga orang dewasa baik laki-laki mapun perempuan. Salah satu media komunikasi yang saat ini dimanfaatkan banyak oleh hamper berbagai kalangan adalah media internet.

Media internet pada dasarnya memiliki fungsi yang sama dengan media massa lainnya. Domininick (2001) dalam Universitas Terbuka (2013) menyebutkan beberapa fungsi komunikasi massa bagi masyarakat, yaitu:

1. Fungsi pengawasan (surveillance)

Fungsi ini terdiri dari 2 bentuk utama, yaitu pengawasan peringatan dan pengawasan instrumental. Media massa menjalankan fungsi pengawasan peringatan, jika menginformasikan tentang ancaman yang disebabkan oleh beberapa hal, misalnya bencana alam, serangan militer, inflasi dan krisis ekonomi. Fungsi pengawasan instrumental dari media massa jika informasi yang disampaikan memiliki kegunaan atau dapat membantu khalayak dalam kehidupan sehari-hari.

2. Fungsi penafsiran (interpretation)

Fungsi ini dijalankan jika media selain menyampaikan fakta dan data kepada khalayak, juga memberi penafsiran terhadap kejadian-kejadian penting. Media memilih dan memutuskan peristiwa-peristiwa mana yang layak dan yang tidak layak disajikan.

3. Fungsi keterkaitan (linkage)

Media massa dapat menjadi alat pemersatu anggota masyarakat yang beragam sehingga membentuk pertalian berdasarkan kepentingan dan minat yang sama tentang sesuatu.

4. Fungsi penyebaran nilai (transmission of values)

Fungsi ini disebut juga sosialisasi. Media massa memperlihatkan kepada khalayak tentang bagaimana seharusnya mereka bertindak dan apa yang diharapkan mereka.

5. Fungsi hiburan (entertainment)

Fungsi hiburan selalu dijalankan oleh setiap media massa. Media yang sangat jelas menjalankan fungsi ini adalah televisi, radio dan tabloid.

Kemudian ada juga fungsi lainnya dari media yaitu fungsi informasi, pendidikan, memengaruhi, fungsi proses pengembangan mental, adaptasi lingkungan dan fungsi memanipulasi lingkungan. Lebih khusus media massa mempunyai fungsi, yaitu fungsi meyakinkan, menganugerahkan status, membius, menciptakan rasa kebersatuan, privitasi dan hubungan parasosial (Karlina, dkk, 2002; dalam Universitas Terbuka, 2013).

Demikian juga dengan internet. Pada dasarnya internet menjadi salah satu sumber informasi yang dapat diakses oleh siapa saja. Internet menjadi lahan informasi yang hamper tak terbatas. Semua orang dapat mengakses informasi yang sesuai dengan kebutuhan yang mereka inginkan. Jadi pada hakekatnya fungsi-fungsi yang melekat pada media massa atau komunikasi massa, terdapat juga pada media internet. 
Pemberdayaan berasal dari kata 'daya' yang berarti memiliki atau mempunyai daya. Pemberdayaan berasal dari bahasa Inggris yaitu empowerment yang dalam Oxford English Dictionary memiliki dua pengertian yaitu: (a) To give ability or enable to (memberi kecakapan/kemampuan atau memungkinkan), dan (b) To give power of authority to (memberi kekuasaan) (Kamil, 2013).

Carlzon dan Macauley (dalam Wasistiono, 1998; dalam Kamil, 2013) mengemukakan bahwa yang dimaksud dengan pemberdayaan adalah "membebaskan seseorang dari kendali yang kaku, dan memberi orang kebebasan untuk bertanggung jawab terhadap ide-idenya, keputusan-keputusannya dan tindakan-tindakannya". Kemudian Carver dan Clatter Back (1995) dalam Kamil (2013) mengartikan pemberdayaan sebagai "upaya memberi keberanian dan kesempatan pada individu untuk mengambil tanggung jawab perorangan guna meningkatkan dan memberikan kontribusi pada tujuan organisasi".

Dari kedua pengertian tersebut, dapat disimpulkan bahwa pemberdayaan adalah usaha yang dilakukan oleh sekelompok orang atau secara individu untuk dapat bertanggungjawab terhadap dirinya sendiri agar dapat berdiri sendiri. Sementara itu, kata pemberdayaan ini sering kali dipasangkan dengan pemberdayaan masyarakat atau pemberdayaan perempuan. Sebelum membahas pemberdayaan perempuan, sebaiknya pemberdayaan masyarakat secara menyeluruh harusnya diketahui terlebih dahulu.

Pemberdayaan masyarakat diartikan sebagai "suatu proses yang membangun manusia atau masyarakat melalui pengembangan kemampuan masyarakat, perubahan perilaku masyarakat, dan pengorganisasian masyarakat" (Hapmi.org, 2013). Dari defisini yang dikeluarkan oleh Hapmi.org, ada tiga (3) tujuan utama dalam pemberdayaan masyarakat yaitu mengembangkan kemampuan masyarakat, mengubah perilaku masyarakat, dan mengorganisir diri masyarakat.

Sementara itu, ada juga yang namanya pemberdayaan perempuan. Sama halnya dengan pemberdayaan masyarakat agar dapat berdayaguna, maka pemberdayaan perempuan lebih disasarkan pada kaum perempuan agar dapat membantu ekonomi keluarga. Pemberdayaan yang dilakukan dalam kegiatan ini adalah berupa pemanfaatan media internet yang selama ini hanya banyak digunakan oleh kaum laki-laki. Sehingga kaum perempuan juga dinilai dapat diberdayakan dalam menggunakan media internet yang pada tujuan akhirnya adalah untuk peningkatan ekonomi keluarga.

Dalam upaya untuk meningkatkan partisipasi perempuan dalam kegiatan ekonomi keluarga melalui pemberdayaan dengan pemanfaatan media internet, pada dasarnya ada lima (5) tingkat pemerataan dalam pemberdayaan perempuan (Saptandari, 2010), antara lain yaitu (1) pemerataan tingkat kesejahteraan; (2) pemerataan akses, yaitu meningkatkan kemampuan mereka masuk ke sektor-sektor untuk mendapatkan informasi, mendapatkan kesempatan bekerja, mendapatkan kesempatan pendidikan yang baik yang sama kedudukannya dengan kaum laki-laki; (3) pemerataan kesadaran; (4) pemerataan partisipasi. Perempuan tidak lagi dianggap sebagai sasaran atau objek dari pembangunan, tetapi ikut serta melakukan perencanaan, ikut serta melaksanakan dan ikut serta 
mengevaluasi program-program yang ditimpakan padanya; dan (5) pemerataan penguasaan, di mana partisipasi perempuan pada tingkat keputusan ini tentunya akan memberikan dampak pada pemberdayaan dan apabila partisipasi ini digunakan maka akses mereka terhadap sumber-sumber ekonomi akan menjadi leboh baik serta menjamin pemerataan terhadap akses sumber dan pembagian manfaat.

Kelima tingkat pembedayaan perempuan tersebut penting sehingga kegiatan ini diawali dengan memberikan informasi kepada kaum perempuan di pesisir Kota Bengkulu mengenai media internet. Perempuan juga seharusnya mampu memanfaatkan media yang ada untuk membantu ekonomi keluarga mereka.

Dari kegiatan yang dilakukan, beberapa hasil yang telah dicapai adalah para peserta kegiatan mengetahui manfaat dari internet. Ceramah yang dilakukan memberikan informasi mengenai komputer, komponen komputer, apa saja sistem aplikasi yang terdapat pada komputer, apa yang dimaksud dengan internet, bagaimana penggunaan dan pemanfaaatan dari internet, situs-situs apa yang ada di internet yang dapat dimanfaatkan dengan maksimal dalam membantu ekonomi keluarga dan terakhir mengenai blog yang dapat digunakan sebagai wadah 'berjualan'.

Kemudian, dari hasil simulasi internet yang dilakukan oleh tim, memperlihatkan bahwa para peserta kegiatan dapat memahami tujuan pembelajaraan ini. Untuk itu, narasumber melakukan simulasi dengan cara tanya jawab diawal penyuluhan atau warming up untuk mengetahui sejauh mana pengetahuan para perempuan dan keluaraga nelayan akan pemanfaatan media internet. Pertanyaan-pertanyaan yang diberikan seperti: apakah itu komputer? Bagaimana pemanfaatan dan dampak dari penggunaan internet dan apa saja situs-situs yang terdapat di internet. Hal ini menunjukkan para perempuan dan keluaraga nelayan ini telah mulai memahami pentingnya pemanfaatan media internet dengan sebaik mungkin. Lebih lanjut, simulasi juga memperlihatkan beberapa gambar tentang tampilan pada blog namun peserta tidak diberi tahu maksud gambaran tersebut. Peserta diminta untuk menjelaskan gambaran yang diperlihatkan. Hasil ini menunjukkan ada peserta yang paham namun juga ada yang tidak paham tentang pemanfaatan media internet.

Pelatihan mengenai internet dan pengenalan komputer tersebut mendapatkan perhatian yang signifikan oleh para perempuan sebagai peserta. Peserta kemudian dapat merasakan manfaat yang besar dari penggunaan internet dalam membantu mereka meningkatkan ekonomi keluarga. Selama ini hasil atau produksi yang mereka lakukan hanya dijual di pasar tradisional atau berjualan disepanjang pinggir pantai, namun sekarang mereka dapat memanfaatkan media internet dalam memasarkan produk yang mereka hasilkan. Dari sini terlihat bahwa media internet bukan hanya sebagai sumber informasi bagi mereka namun juga memiliki fungsi lain yaitu fungsi ekonomi.

Dapat disimpulkan bahwa hasil yang dicapai untuk meningkatkan pengetahuan perempuan akan media internet telah mulai terlihat. Peserta menunjukkan antusias dan terlihat salah seorang peserta telah memiliki email dan dapat mengakses situs-situs 
internet. Sehingga dari sinilah pemberdayaan perempuan dapat dilakukan untuk meningkatkan kesejateraan kaum nelayan.

Kegiatan ini menghasilkan sambutan baik yang cukup signifikan dari kalanagan peserta maupun dari pihak kelurahan. Sehingga diharapkan kegiatan yang telah berlangsung tersebut menjadi salah satu program pemberdayaan bagi perempuan untuk dapat menggunakan media yang ada dalam meningkatkan ekonomi keluarga. Media internet khususnya tidak lagi menjadi sebuah barang 'aneh' bagi perempuan namun media ini menjadi salah satu penggerak perekonomian keluarga mereka.

\section{KESIMPULAN DAN SARAN}

\section{Kesimpulan}

Dari kegiatan yang dilakukan, dapat disimpulkan bahwa media internet yang dikenalkan pada para peserta mendapatkan sambutan yang positif dan antusias karena selama ini mereka hanya mendengar istilah internet tanpa tahu apa sebenarnya internet serta apa kegunaan internet.

\section{Saran}

Saran dari kegiatan ini adalah adanya peran pemerintah lokal dalam memfasilitasi masyarakat pesisir untuk dapat mengakses internet secara gratis atau adanya program internet untuk masyarakat.

\section{DAFTAR PUSTAKA}

....... 2012, Manfaat Positif dan Negatif dari Penggunaan Internet, <http://xiaolichen14.wordpress.com/2012/10/23/manfaat-positif-dan-negatif-daripenggunaan-internet/> diakses pada 1 September 2013.

Adeni, Susri., Kartika, Titiek., Andani, Apri., 2010, Poverty Reduction Towards LowIncome Family Economy Security Among Women Group at The Coastal Areas in Bengkulu, A Research Report.

Hapmi.org., 2013, Apa itu Pemberdayaan Masyarakat?, <http://hapmi.org/2013/01/10/ apa-itu-pemberdayaan-masyarakat/> diakses pada 1 September 2013.

Kamil, $\quad$ Mustofa., 2013, Pengertian Pemberdayaan, $<$ http://www.google.com/url?sa=t\&rct=j\&q=\&esrc= s\&source=web\&cd=7\&ved=0CF4QFjAG\&url=http\%3A\%2F\%2Ffile.upi.edu\%2FD irektori\%2FFIP\%2FJUR._PEND._LUAR_SEKOLAH\%2F196111091987031001M USTOFA_KAMIL\%2FPengertian_Pemberdayaan.pdf\&ei=Y0uEUvzYLYKAiQfW o4GoBQ\&usg=AFQjCNEa3TsscSMK_slvPF1claBzVzAgg\&sig2=YvgFIFXyHnou vhCVA7jfQw\&bvm=bv.56343320,d.aGc> diakses pada 1 September 2013. 
Saptandari, Pinky., 2010, Lima Tingkat Pemberdayaan Perempuan, Jurnal Masyarakat dan Kebudayaan Politik, Vol. 12. No.2, <http://mkp.fisip.unair.ac.id/index.php? option=comcontent $\&$ view $=$ article $\&$ id $=\quad$ 158:-lima-tingkat-pemberdayaanperempuan \&catid=34:mkp\&Itemid=61> diakses pada 1 September 2013.

Universitas Terbuka, 2013, Peran dan Fungsi Media Massa dalam Kehidupan Manusia, < http://www.ut.ac.id/html/suplemen/skom4315/f1b.htm> diakses pada 1 September 2013.

Yuhefizar, Sejarah Komputer, IlmuKomputer.com; <http://fadel05.tripod.com/ komputer/komputer.html > diakses pada 1 September 2013. 